\title{
Cultivation of the oil-producing yeast microorganism Rhodotorula mucilaginosa for sustainable production of bio-oil energy
}

\author{
Shu-Yao Tsai ${ }^{1,2, *}$, Hsuan-Ti Yu1, Chun-Ping Lin ${ }^{1,3,4, *}$ \\ ${ }^{1}$ Department of Food Nutrition and Health Biotechnology, Asia University, 500, Lioufeng Rd., Wufeng, Taichung, 41354 \\ Taiwan; sytsai@asia.edu.tw (S.-Y. Tsai); tiffanyyu2357819@gmail.com (H.-T. Yu); cp.lin@asia.edu.tw (C.-P. Lin) \\ ${ }^{2}$ Department of Biotechnology, National Formosa University, 64, Wunhua Rd., Huwei Township, Yunlin County, 632301 \\ Taiwan \\ ${ }^{3}$ Office of Environmental Safety and Health, Asia University, 500, Lioufeng Rd., Wufeng, Taichung, 41354 Taiwan \\ ${ }^{4}$ Department of Medical Research, China Medical University Hospital, China Medical University, 91, Hsueh-Shih Rd., \\ Taichung, 40402 Taiwan \\ *Corresponding authors: E-mail: sytsai@ asia.edu.tw (S.-Y. Tsai); cp.lin@asia.edu.tw \& chunping927@gmail.com (C.-P. \\ Lin)
}

\begin{abstract}
This study was focused on the development of oil-producing microorganisms to generate lipids. The yeast Rhodotorula mucilaginosa (R. mucilaginosa) was selected for liquid-state cultivation, and the conditions for growth of the yeast cells were assessed. Additionally, the relationships between different nutrient elements and the growth of $R$. mucilaginosa were explored. The lipid accumulation of $R$. mucilaginosa is increased under nitrogen-restricted conditions. As the concentration of the carbon source increases, the accumulation of lipids is increased. However, if the carbon source concentration is further increased, the growth of yeast is inhibited. From a large-scale liquid fermentation culture with a fixed inoculation amount of $5 \%$, and from a batch of culture experiments, it was determined that a suitable oil-producing culture was obtained on the 6th day, and the optimum conditions involved a carbon source concentration of $60 \mathrm{~g} / \mathrm{L}$, a nitrogen source concentration of $0.5 \mathrm{~g} / \mathrm{L}$, and $\mathrm{K}_{2} \mathrm{KHO}_{4}$ concentration of $7.0 \mathrm{~g} / \mathrm{L}$. After utilizing different carbon sources in this study, it was found that glucose was the carbon source most conducive to the accumulation of $R$. mucilaginosa lipids. In addition, the extraction method and solvent for the extraction of $R$. mucilaginosa lipids were chosen. The acid-heat method using the green organic solvent ethyl acetate exhibited the best performance for extraction of yeast lipids under environmentally friendly and safe conditions. The analysis of lipids showed that the fatty acids obtained primarily contained C16:0, C18:1 and C18:2, and especially C18:1 (41\%) lipids, indicating that $R$. mucilaginosa lipids are a good bio-oil source for the production of biodiesel.
\end{abstract}

Keywords: Oil-producing microorganism; Rhodotorula mucilaginosa; liquid fermentation; extraction; green organic solvent 


\section{Introduction}

Microbial oil is a renewable resource, so the use of microbial fermentation to produce bio-oil instead of using petroleum resources is of great significance. Except for microalgae, which require large open spaces, fertilizers and sunlight to grow effectively, the other oil-production microorganisms are not affected by geography and climate and do not need farmland and expensive sources of nutrition [1]. Oil-producing microorganisms, especially yeast, can produce large amounts of lipids and also have a high growth rates spanning 24 continuous hours; therefore, the production times are short and uniform, with no limiting requirements for cultivating space [2]. Among oil-production technologies, microbial oil production is superior to production of either vegetable oil or algae oil [3-5]. Compared to other microorganisms, yeast culture substrates have a lower cost than cultures using agricultural and industrial residues [6-8].

Rhodotorula mucilaginosa (referred to as R. mucilaginosa) was used to produce single-cell lipids (SCOs), and the most suitable medium composition and lipid production conditions were found by exploring the different nutrient elements in the medium. There are several new methods known for increasing lipid production in oil-producing yeast, such as genetic engineering to improve the strain, modifying the culture conditions (temperature, $\mathrm{pH}$, stirring rate), and improving the bioreactor used for culturing (batch or sequencing batch model). The nature of fatty acids synthesized by oil-producing yeast depends on the nutrient content of the provided medium and on culture conditions $[9,10] . R$. mucilaginosa belongs to the phyla Basidiomycota, Puccinia, and Spore. It is suitable for growth in an environment of $20 \sim 30{ }^{\circ} \mathrm{C}$ and $\mathrm{pH} 5 \sim 6$; like those of vegetable oils, the lipid produced by $R$. mucilaginosa has a high proportion of unsaturated fatty acids suitable for producing biodiesel. In addition to synthetic fats, $R$. mucilaginosa can also be fermented to prepare products with biological functions, such as astaxanthin, enzyme reagents and carotenoids, which are widely used in energy, medicine, food, cosmetics, feed additives, and other applications. Yeast lipids mainly include triglycerides, such as oleic acid (C18:1), linoleic acid (C18:2), stearic acid (C18:0), palmitic acid (C16:0) or palmitoleic acid (C16:1) [11,12]. However, the effective synthesis of lipids depends largely on the culture conditions.

In addition, the key factor affecting the biosynthetic pathway of $R$. mucilaginosa is the ratio of carbon to nitrogen [13]; medium adjustment is essential to the production of SCO from yeast. The accumulation of microbial lipids is divided into two stages: the growth period of the bacteria and the lipid accumulation period. The growth phase of the bacteria occurs when the strain uses enough medium to multiply cells. When nitrogen is exhausted from the medium, the cells no longer proliferate, and the excess carbon source is converted into lipids that are stored in the cell. In the lipid accumulation period, a low carbon-nitrogen ratio is conducive to bacterial accumulation, and a high carbon-nitrogen ratio is conducive to lipid accumulation. Therefore, the carbon-nitrogen ratio directly affects the lipid 
production of the strain. Selecting appropriate carbon and nitrogen sources to cultivate yeast is important for achieving high lipid production [14]. Different oil-producing microorganisms have their preferred carbon sources, and different carbon sources have different effects on the growth of microorganisms. Compared to other organic carbon sources, when glucose is the main carbon source, it can provide different types of oil-producing microorganisms with higher bacterial organisms. Generally, glucose is the most common medium for the accumulation of high levels of carbon source lipids [15-19]. Inorganic salts generally required by microorganisms are those containing sulfate, potassium, iron, magnesium, sodium and other elements. Compared with carbon, nitrogen and phosphorus, micronutrients can only support growth to a limited extent; however, micronutrients play a vital role in the growth and metabolism of bacteria, and they affect nutrition in cells [20].

Typical microbial growth has four phases: these are the lag phase, logarithmic phase, stationary phase, and decay phase. When microorganisms are inoculated from the original culture medium for fermentation in a new medium, they generally do not start to grow and reproduce immediately; only after the process of environmental adaptation can new cells be produced. In the lag phase, cells do not reproduce but only increase in size. After adaptation, their physiological and metabolic functions begin to flourish, and they begin to reproduce and enter the logarithmic phase. Moreover, when cell reproduction reaches its peak, the total number of cells will not increase further because the consumption of nutrients and metabolites in the culture medium inhibits the reproduction process. The lipid content of microbial cells varies significantly with the growth stage of the microorganisms, and the suitable cultivation times for different microorganisms also vary. Therefore, measuring the growth curve of microorganisms is helpful for understanding and mastering the laws of growth for the microorganisms. If the culture time is insufficient, the total number of bacteria will be small, which will affect lipid production; if the culture time is too long, the cells easily deform and auto-dissolve, making it difficult to collect synthetic lipids from the medium [15-19].

The GlaxoSmithKline (GSK) solvent guide introduces the relative ranking of solvents in different categories ( 1 is the worst and 10 is the best). Based on the color-coding method for choosing safer and less toxic solvents, there are three levels: they are preferred (green), usable (yellow) or avoided (red) [21-23]. Ethyl acetate was used as the main solvent for extracting intracellular yeast lipids in this study, and it is an organic solvent that conforms to "green chemistry" principles and has properties very similar to those used in lipid extraction. It has been proven to be an excellent choice for lipid and protein extraction [24]. Lu et al. (2016) [25] studied single-solvent extraction and compared the efficiencies of ethyl acetate, acetone, ethanol, and n-hexane in recovering lipids and observed that ethyl acetate has excellent selectivity in neutral lipid extraction, higher than that of chloroform [26]. Fine et al. (2013) [27] also used different solvents or mixtures and found that ethyl acetate is more polar than hexane, can improve the extraction rate of lipids and is less toxic than a chloroform-methanol blended 
solvent. Ethyl acetate has been used to extract lipids from various plant seeds [28,29]. Although it has similar properties to $\mathrm{n}$-hexane, it is cheaper and safer when subjected to waste treatment processes [28].

Lipid extraction is carried out with dry yeast powder or directly with wet bacteria [30]. To release lipids in bacteria, solvents can be used directly or auxiliary solvents can be used for cell destruction (mechanical, chemical or biological methods) to increase the efficiency of lipid extraction [31]. The cell wall is first physically destroyed so that the lipid molecules mix easily with the solvent. In addition, there are many factors that affect the efficiency and cost of lipid extraction: these include solvent selection, extraction time, temperature, and cell disruption method. The optimization of these factors is key for efficient and low-cost oil extraction [32]. The chemical acid-heat treatment of bacterial cells is mainly based on the acid hydrolysis of sugar polymers and proteins in the cell wall by hydrochloric acid or sulfuric acid, which makes the original compact cell wall loosen; then the cell wall is further destroyed with a boiling water bath and quick freezing treatment, and the organic solvent can extract the lipids in the cells effectively. This process has been effectively used as a pretreatment method for extracting bio-oil [33]. Furthermore, ultrasound-assisted extraction (UAE) uses solvent-assisted ultrasonic extraction to produce a strong cavitation effect that destroys cells, allows the solvent to penetrate the cells, and improves the extraction rate. Ultrasonic waves are mechanical sound waves with high energy that produce a dispersion effect on the cell wall, causing intracellular substances to enter the solvent medium and be easily dissolved. Therefore, as compared with simple solvent extraction methods, ultrasonic-assisted extraction is more efficient for cell division and lipid extraction [32].

The storage-related thermal stability and physical response to low-temperature conditions for $R$. mucilaginosa lipids are also used as references for the safe production, storage, and transportation conditions of biodiesel. It is also known that yeast lipids have good thermal stability, high calorific value, and high kinematic viscosity [34]. Therefore, $R$. mucilaginosa lipids have certain prospects that are useful in the production of biodiesel. Scale-up cultivation can be used to quantify lipid production by $R$. mucilaginosa and ensure the energy sustainability and environmental sustainability of biofuel production by oil-producing microorganisms.

\section{Materials and Methods}

\subsection{Strains, Inoculum, Culture, and Liquid fermentation}

Rhodotorula mucilaginosa (BCRC 22360) was purchased from the Bioresources Collection and Research Center (BCRC) of the Food Industry Research and Development Institute (FIRDI) in Hsinchu, Taiwan. The strain was stored in YPD medium ( $2 \%$ glucose, $1 \%$ yeast extract, $2 \%$ peptone and $2 \%$ agar) at $4{ }^{\circ} \mathrm{C}$, the culture temperature was $25^{\circ} \mathrm{C}$, and the culture time was 6 days. A $5 \mathrm{~mm} \times 5$ $\mathrm{mm}$ piece of a well-growing strain was placed on a plate and inserted into $100 \mathrm{~mL}$ of liquid medium 
(each liter contains: glucose $10 \mathrm{~g}$, yeast extract $3 \mathrm{~g}$, peptone $5 \mathrm{~g}$ and malt extract $3 \mathrm{~g}$ ) in a $250 \mathrm{~mL}$ Erlenmeyer flask and shaken at $100 \mathrm{rpm}$ and $25^{\circ} \mathrm{C}$ for 15 days. Then the liquid containing the wellgrowing strain was inoculated into the fermentation medium with 5\% inoculum, $200 \mathrm{~mL}$ liquid medium (each liter contains: glucose $40 \mathrm{~g}$, yeast extract $1.5 \mathrm{~g},\left(\mathrm{NH}_{4}\right){ }_{2} \mathrm{SO}_{4} 2 \mathrm{~g}, \mathrm{KH}_{2} \mathrm{PO}_{4} 7 \mathrm{~g}$ and $\mathrm{MgSO}_{4}$. $7 \mathrm{H}_{2} \mathrm{O} 1.5 \mathrm{~g}$ ) in a $500 \mathrm{~mL}$ Erlenmeyer flask and shaken at $100 \mathrm{rpm}$ and $25{ }^{\circ} \mathrm{C}$ for 15 days [15-19].

\subsection{Suitable liquid culture conditions}

A $200 \mathrm{~mL}$ sample of liquid culture medium (4\% glucose, $0.15 \%$ yeast extract, $0.2 \%(\mathrm{NH} 4)_{2} \mathrm{SO}_{4}$, $0.7 \% \mathrm{KH}_{2} \mathrm{PO}_{4}$ and $0.15 \% \mathrm{MgSO}_{4} \cdot 7 \mathrm{H}_{2} \mathrm{O}$ ) was added to a $500 \mathrm{~mL}$ Erlenmeyer flasks and sterilized, the inoculum $10 \mathrm{~mL}$ was inserted into the sterile box and covered with culture paper, and then the flask was shaken at $100 \mathrm{rpm}$ and $25^{\circ} \mathrm{C}$ for $0,3,6,9,12$ or 15 days. The carbon source concentration was $40,60,80$ or $100 \mathrm{~g} / \mathrm{L}$, and $200 \mathrm{~mL}$ of liquid medium (with the chosen carbon source concentration, $0.15 \%$ yeast extract, $0.2 \%\left(\mathrm{NH}_{4}\right)_{2} \mathrm{SO}_{4}, 0.7 \% \mathrm{KH}_{2} \mathrm{PO}_{4}$ and $\left.0.15 \% \mathrm{MgSO}_{4} \cdot 7 \mathrm{H}_{2} \mathrm{O}\right)$ was put it into a 500 $\mathrm{mL}$ Erlenmeyer flask and sterilized; $10 \mathrm{~mL}$ of the inoculum was inserted into the sterile box, covered with culturing paper, and shaken for culturing at $100 \mathrm{rpm}$ for 6 days at a culture temperature of $25^{\circ} \mathrm{C}$ [13-20]. The nitrogen content source concentration was $0.5,1.0,1.5$, or $2.0 \mathrm{~g} / \mathrm{L}$, and $200 \mathrm{~mL}$ of liquid medium (containing $60 \mathrm{~g} / \mathrm{L}$ of the carbon source, the chosen nitrogen source concentration, $0.2 \%$ $\left(\mathrm{NH}_{4}\right) 2 \mathrm{SO}_{4}, 0.7 \% \mathrm{KH}_{2} \mathrm{PO}_{4}$ and $0.15 \% \mathrm{MgSO}_{4} \cdot 7 \mathrm{H}_{2} \mathrm{O}$ ) was put it into a $500 \mathrm{~mL}$ Erlenmeyer flask and sterilized; then $10 \mathrm{~mL}$ of the inoculum was inserted into the sterile box, covered with culture paper, and shaken for culturing at $100 \mathrm{rpm}$ at the optimum culture temperature for 6 days. All experiments were performed in triplicate [15-19].

\subsection{Biomass and lipid analysis}

The cultured yeast fermentation broth was centrifuged for $10 \mathrm{~min}$ with $50 \mathrm{~mL}$ of fermentation broth, the supernatant was removed, and the sediment was washed several times with deionized water. The cells were collected by centrifugation, then dried at $50{ }^{\circ} \mathrm{C}$ to a constant weight, and the dry weight of the cells was measured. The dry weight is expressed in $\mathrm{g} / 100 \mathrm{~mL}$. We took $50 \mathrm{~mL}$ of fermentation broth to collect yeast cells by centrifugation, added $20 \mathrm{~mL}$ of $1 \mathrm{~mol} / \mathrm{L}$ hydrochloric acid solution, and placed the sample in a water bath at $60{ }^{\circ} \mathrm{C}$ for $10 \mathrm{~min}$ to obtain broken cells. Ten milliliters of ethyl acetate was mixed with the yeast cells, ultrasonically shaken for $30 \mathrm{~min}$, and then centrifuged for 20 min to collect the extract. Then, $10 \mathrm{~mL}$ of ethyl acetate was added to repeat the extraction of yeast lipids, and the two extracts were combined and isothermally concentrated to dryness at $50{ }^{\circ} \mathrm{C}[30]$.

\subsection{Selection of extraction conditions and solvent}

The aim was to study different organic solvents, such as dichloromethane, n-hexane, and ethyl acetate, 
to evaluate the lipid extraction of $R$. mucilaginosa and compare the effects of different solvents. Acidhot extraction was used to simultaneously explore the influence of different hydrochloric acid concentrations of $1,2,3$, and $4 \mathrm{M}$ on the amount of extracted lipid, and to find the appropriate concentration of hydrochloric acid for extraction. Next, the influence of the acid-heat extraction temperatures 60,80 , and $100{ }^{\circ} \mathrm{C}$ on lipid extraction was assessed. A fixed acid-heat extraction with selected hydrochloric acid concentration and the hot-water bath temperature can be used consistently for subsequent yeast lipid extraction. Furthermore, the influence of ultrasonic (Ultrasonic Processor DC200, Delta Electronics, Taiwan) (40 kHz, $200 \mathrm{~W})$ vibration on the lipid weight of the bacterial body has also been discussed [26-33]. All experiments were carried out in triplicate.

\subsection{Fatty acid composition and biodiesel analysis}

To approximately $100 \mathrm{mg}$ of yeast lipid in $10 \mathrm{~mL}$ of $\mathrm{n}$-hexane, we added $1 \mathrm{~mL}$ to $0.5 \mathrm{~mL}$ of internal standard solution, put the solution in a brown glass bottle, mixed in $1 \mathrm{~mL}$ of a $1 \mathrm{~N}$ solution of potassium hydroxide in methanol, filled the bottle with nitrogen and mixed with a vortex mixer for 30 sec, placed the bottle in an $80^{\circ} \mathrm{C}$ water bath for $15 \mathrm{~min}$, removed it and allowed it to cool, added $1 \mathrm{~mL}$ of boron trifluoride-methanol solution, filled the bottle with nitrogen, mixed the solution with a vortex mixer for $30 \mathrm{sec}$, and then placed the bottle in a $100{ }^{\circ} \mathrm{C}$ water bath for $15 \mathrm{~min}$. After removing and cooling it, we added $1 \mathrm{~mL}$ of $\mathrm{n}$-hexane, mixed the solution with a vortex mixer for $1 \mathrm{~min}$, added $5 \mathrm{~mL}$ of saturated sodium chloride solution and shook gently, let the mixture stand for layering, then collected the supernatant and injected it into the gas chromatography/mass spectrometer for detection of the fatty acid composition by gas chromatography/mass (GC/Mass) with an Agilent 8975/7890A system (Agilent Technologies Inc., Santa Clara, CA, USA). The measurement conditions were as follows: chromatographic column initial temperature: $170{ }^{\circ} \mathrm{C}$ for $40 \mathrm{~min}$; heating rate: $3^{\circ} \mathrm{C} / \mathrm{min}$; final temperature: $200{ }^{\circ} \mathrm{C}$ for $50 \mathrm{~min}$; detector temperature: $300{ }^{\circ} \mathrm{C}$; injector temperature: $250{ }^{\circ} \mathrm{C}$; injection volume: $1 \mu \mathrm{L}$; mobile phase gas helium flow rate: $0.75 \mathrm{~mL} / \mathrm{min}$; and split ratio: 40:1 [34].

\subsection{Differential scanning calorimetry (DSC) thermal analysis}

Differential scanning calorimetry (TA Q20-RCS90, TA Instruments, Newcastle, DE, USA) was used to measure the thermal stability and low-temperature characteristics of lipids. The sample preparation conditions should be kept as consistent as possible to reduce the fluctuation of the baseline, and the instrument should be calibrated before the test. Approximately $1.5 \mathrm{mg}$ of the yeast lipid and biodiesel were sealed in $20 \mu \mathrm{L}$ aluminum lips, hermetic 900794.901, and a special tool for the TA DSC instrument was used to tighten the seal. In all experiments, high-purity nitrogen was used as the purge gas, with a flow rate of $50 \mathrm{~mL} / \mathrm{min}$. The samples were heated at rates of 4,6 or $8{ }^{\circ} \mathrm{C} / \mathrm{min}$, with a temperature range of $30-300{ }^{\circ} \mathrm{C}$; the initial temperature was 30 to $70{ }^{\circ} \mathrm{C}$, the sample was heated at rate 
of 4,6 , or $8{ }^{\circ} \mathrm{C} / \mathrm{min}$, then held at $70{ }^{\circ} \mathrm{C}$ for $3 \mathrm{~min}$, and next cooled to $-60{ }^{\circ} \mathrm{C}$ for determining the lowtemperature characteristics and thermal stability of the samples [35].

\subsection{Heat of combustion measurement}

One gram of yeast lipid was carefully weighed and placed on the test dish, which was then placed on the measuring device of the Parr 1341 oxygen bomb calorimeter instrument (Parr Instrument Company, Moline, IL, USA). We cut the combustion wire and used fused Ni alloy wire (Paar item No. $45 \mathrm{C} 10)$ of approximately $10 \mathrm{~cm}$ in length. The two ends of the lead were connected to the two electrodes of the bomb. The loading dish was put into the bomb, and high-purity $97 \%$ oxygen was added into the bomb until the pressure in the bomb reached 20 bar. Two liters of deionized water was allowed to stand for $24 \mathrm{~h}$ and then poured into the water tank. The burner was put into the stainlesssteel water tank, and the burner and the $2 \mathrm{~L}$ water tank were put into the card instrument, and the wires were connected to start the stirrer. The stirrer was operated for five minutes to allow the internal water temperature to reach equilibrium, the system was then ignited, and the temperature rise was recorded. After the experiment was completed, the inner wall of the burner and the surface of the upper cover were cleaned with distilled water and the cleaning liquid was collected. The unburned lead wire was removed from the electrode to measure the length. The cleaning solution was collected and titrated with $0.0709 \mathrm{~N}$ sodium carbonate solution and methyl orange was used to determine the endpoint of the titration; all experiments were performed in triplicate [34].

\subsection{Measurement of isothermal $40{ }^{\circ} \mathrm{C}$ kinematic viscosity}

We used a Cannon-Fenske75 U540 viscometer tube (Cannon Instrument Company, State College, PA, USA) fixed in a $40{ }^{\circ} \mathrm{C}$ isothermal water tank with a bracket, added $10 \mathrm{~mL}$ of yeast lipid to the viscometer tube, placed it in a $40{ }^{\circ} \mathrm{C}$ water bath for $10 \mathrm{~min}$, and measured its kinematic viscosity. We used a safety suction ball to suck the sample and keep the oil level at $5 \mathrm{~mm}$ above mark $\mathrm{C}$. We started measurement of the oil flowing downwards from the capillary tube under the action of gravity. The timing was started when the oil dropped to mark $\mathrm{C}$ and it ended when the oil dropped to mark $\mathrm{E}$. We recorded the time (seconds) required for the oil level to flow from mark $\mathrm{C}$ to mark $\mathrm{E}$ and multiplied it by the constant of the viscometer to obtain the isothermal $40{ }^{\circ} \mathrm{C}$ kinematic viscosity of the yeast oil. Each experiment was conducted in triplicate [34].

\section{Results and discussion}

\subsection{Rhodotorula mucilaginosa culture time and liquid medium composition}

Figures 1 (a) and (b) show the morphology of the R. mucilaginosa strain after 0-15 days of culturing 
in liquid medium (see photographs in Figure 1 (c)). The color of the medium changed to orange on the 3rd day, and then the color darkened to orange-red after the 6th day. Moreover, R. mucilaginosa was cultured for two days and the dry cells were extracted; then, the biomass of the cells and the amount of accumulated were evaluated. Table 1 shows that the culture process for $R$. mucilaginosa conforms to the microbial growth metabolism curve over time. Figure 2 shows that $R$. mucilaginosa was in the lag phase for four days after the initial culture, and the increase in its lipid content was not obvious. After the 4th day, the yeast began to accumulate secondary metabolite fatty acids; the logarithmic phase occurred in days 4-6 days, during which time the yeast mass multiplied in the rapid division and multiplication stage. The highest mass was observed on the 6 th day, and the lipid content began to decline after the 8th day. Table 1 shows that extraction of the dry cells of $R$. mucilaginosa collected at 6 days resulted in the highest level of lipids obtained.

\subsection{Influence of liquid medium composition on R. mucilaginosa lipid production}

\subsubsection{Carbon source}

Initially, glucose was used as the main carbon source, and four carbon source concentrations of 40, 60, 80 , and $100 \mathrm{~g} / \mathrm{L}$ were selected to evaluate the accumulations of biomass and lipids. Table 2 shows that the yeast cell lipid content tended to increase as the carbon source concentration was increased. In terms of the accumulation of lipids by yeast, the $60 \mathrm{~g} / \mathrm{L}$ carbon source with glucose provided the highest lipid content, which accounted for approximately $15 \%$ of the dry yeast cell weight. The ratios of the carbon source and nitrogen source were suitable for effective growth of the yeast. For the yeast lipid content, when the carbon source concentration was $40 \mathrm{~g} / \mathrm{L}$, the carbon source was in short supply, and the yeast could no longer grow after depleting the carbon source. In addition, if the carbon source concentration was higher than $60 \mathrm{~g} / \mathrm{L}$, the lipid content gradually decreased, which should be due to the "oversupply" of carbon sources.

The synthesis of lipids shows that when the carbon source level is high and the nitrogen source level is low, the yeast produces lipids well, but when the carbon source is too high, production will be inhibited. In addition, Table 2 also shows that when considering the accumulated lipid content of the yeast, the carbon source was fixed at an initial level of $60 \mathrm{~g} / \mathrm{L}$, and this was used for the subsequent shake flask amplification experiment.

Moreover, in determining the influences of different carbon sources on the growth of yeast, we used other carbon source substrates and selected low-cost glycerin and molasses as biomass sources with which we planned to reduce the production cost of bio-oil and improve the market competitiveness of bio-oil. The concentrations of the various fixed carbon sources glucose, glycerol, and molasses were $60 \mathrm{~g} / \mathrm{L}$, and the experimental results are shown in Figure 3. The results showed that molasses at $0.76 \mathrm{~g} / 100 \mathrm{~mL}$ had the highest biomass content, followed by glucose and glycerol, but 
the use of glucose as a carbon source resulted in the highest lipid content, with lipid accumulation above $13 \%$. According to these results, the concentration of glucose biomass was lower than that of molasses; glucose was the best carbon source for cell lipid synthesis, so glucose will be used as the main carbon source. We also confirmed that low-cost carbon sources such as glycerol and molasses can be used as competitive substitutes for microbial lipid production.

\subsubsection{Nitrogen source}

The fixed carbon source concentration was $60 \mathrm{~g} / \mathrm{L}$, and the effects of the different nitrogen source concentrations $0.5,1.0,1.5$, and $2.0 \mathrm{~g} / \mathrm{L}$ on the growth and lipid accumulation of $R$. mucilaginosa were explored. Table 3 shows that the initial nitrogen source concentration of $1.5 \mathrm{~g} / \mathrm{L}$ resulted in the highest biomass, $0.76 \mathrm{~g} / 100 \mathrm{~mL}$, but the lipid content was only $10.25 \%$. When the initial nitrogen source concentration was $0.5 \mathrm{~g} / \mathrm{L}$, the biomass obtained was only $0.60 \mathrm{~g} / 100 \mathrm{~mL}$, but the lipid content reached its highest level at $16.11 \%$. In addition, when the nitrogen source concentration was at the highest concentration of $2.0 \mathrm{~g} / \mathrm{L}$, the biomass and lipid content obtained were only $0.71 \mathrm{~g} / 100 \mathrm{~mL}$ and $9.92 \%$, respectively. Therefore, it was proven that when the nitrogen source content of the medium is too low, it is not conducive to the growth of $R$. mucilaginos $a$. Under culture conditions with excessive carbon sources and limited nitrogen sources, yeast grows slowly and $R$. mucilaginosa can continue to accumulate lipids produced from glucose. When the yeast was used for lipid production, the carbon source concentration was fixed at $60 \mathrm{~g} / \mathrm{L}$ and a suitable nitrogen source concentration of $0.5 \mathrm{~g} / \mathrm{L}$ were selected for the subsequent amplification experiment.

\subsection{3 $\mathrm{KH}_{2} \mathrm{PO}_{4}$ concentration}

Due to the influence of $\mathrm{KH}_{2} \mathrm{PO}_{4}$ concentration on the growth of yeast, phosphorus is known to be responsible for regulating most cell activity and metabolism. According to the abovementioned results, a carbon source concentration of $60 \mathrm{~g} / \mathrm{L}$ and a nitrogen source concentration of $0.5 \mathrm{~g} / \mathrm{L}$ were cultivated with shaking at $25{ }^{\circ} \mathrm{C}$ and $100 \mathrm{rpm}$ for 6 days to select among three $\mathrm{KH}_{2} \mathrm{PO}_{4}$ concentrations, 1.0, 3.0, and $7.0 \mathrm{~g} / \mathrm{L}$, for cultivation. Then, the influence of $\mathrm{KH}_{2} \mathrm{PO}_{4}$ on yeast growth and lipid accumulation during liquid culture was assessed. Table 4 shows that increasing the $\mathrm{KH}_{2} \mathrm{PO}_{4}$ concentration increased biomass and lipid contents. When the $\mathrm{KH}_{2} \mathrm{PO}_{4}$ concentration reached $7.0 \mathrm{~g} / \mathrm{L}$, the yeast biomass reached $0.59 \mathrm{~g} / 100 \mathrm{~mL}$, the lipid yield reached $0.15 \mathrm{~g} / 100 \mathrm{~mL}$, and the lipid production rate from multiple extractions was as high as $25 \%$. Thus, we found that adding $\mathrm{KH}_{2} \mathrm{PO}_{4}$ is beneficial to $R$. mucilaginosa growth and lipid accumulation; therefore, a fixed carbon source concentration of $60 \mathrm{~g} / \mathrm{L}$, a nitrogen source concentration of $0.5 \mathrm{~g} / \mathrm{L}$, and a $\mathrm{KH}_{2} \mathrm{PO}_{4}$ concentration of $7.0 \mathrm{~g} / \mathrm{L}$ were used for subsequent amplification of lipid production.

\subsection{Influences of different extraction methods on R. mucilaginosa lipids}


After the yeast was pretreated, and due to the effective release of lipids from yeast cells, the yeast lipids must be extracted using appropriate methods. We compared three different extraction methods, Soxhlet ether extraction, the organic solvent method and the acid-heat method, to determine their effects on the extraction of lipids from $R$. mucilaginosa and to find a suitable extraction method in this study. Table 5 shows that, among the three methods studied, the Soxhlet extraction and the organic solvent method were less effective than the acid-heat method. This is because yeast lipids are intracellular products and the efficiency of direct extraction with organic solvents is not high. Thus, the extraction requires acid hydrolysis to break the yeast cell walls, and then the hot water bath treatment is applied to release a large amount of lipid; the lipid content obtained from acid-heat extraction is as much higher than that from the Soxhlet ether extraction. Therefore, we used acid-heat extraction as the extraction method for lipid production.

Since solvents account for a large part of the extraction cost, it is necessary to find a cheaper and safer extraction solvent. Furthermore, the different organic solvents dichloromethane-methanol (1:1), n-hexane, and ethyl acetate were also studied to evaluate the lipid extraction of $R$. mucilaginosa. Using the extraction results, a suitable extraction solvent was selected after consideration of environmental protection factors. Table 6 shows data for the use of the acid-heat method with a $4 \mathrm{M} \mathrm{HCl}$ solution in determining the lipid contents obtained by extractions with different organic solvents. The three organic solvents were compared using the same acid-heat extraction method, and the extraction efficiency of ethyl acetate was the highest. Among the organic solvents considered, ethyl acetate is an excellent choice with low toxicity and low cost. The results of this study also proved that ethyl acetate can replace other, toxic solvents and operational costs can be reduced by recycling.

In addition, the $R$. mucilaginosa lipid is an intracellular product that is wrapped by the yeast cell wall and cell membrane. Comparing Tables 5 and 6, we found that the efficiency of direct extraction with organic solvents was not high. To achieve improved production efficiency, it is necessary to break the yeast cell walls first. The acid-heat method was used to break the yeast cell walls, mainly by using hydrochloric acid and the sugar and protein in the cells to loosen the originally intact cell wall; then, during boiling in a water bath and a rapid cooling treatment, the yeast cell wall was further destroyed. Here, we used hydrochloric acid solution as the single variable, with other conditions unchanged, to further understand the effect of the different hydrochloric acid concentrations $1,2,3$, and $4 \mathrm{M}$ on the extraction of broken yeast cells. In Table 7, the acid-heat method involved $\mathrm{HCl}$ concentrations of 1-4 $\mathrm{M}$, the lipid contents were $11,15,18$, and $20 \%$, respectively, and the highest lipid content was obtained with $4 \mathrm{M} \mathrm{HCl}$. However, it was found that when the extraction was attempted with a concentration of $5 \mathrm{M}$ hydrochloric acid, the extraction could not be performed. The possible cause was that the concentration of hydrochloric acid was too high and led to lipid emulsification. Therefore, hydrochloric acid concentrations of $5 \mathrm{M}$ and above were not considered. 
Moreover, Figure 4 displays the extraction effect of the different hot water bath temperatures 60, 80 and $100{ }^{\circ} \mathrm{C}$. The results show that the effect of the $100{ }^{\circ} \mathrm{C}$ water bath on yeast lipid acid-heat extraction is greater than those of the 60 and $80^{\circ} \mathrm{C}$ hot water baths. This means that when the hot water bath temperature was $100^{\circ} \mathrm{C}$ the cell wall breakage by hydrolysis was more effective. Compared with a $60{ }^{\circ} \mathrm{C}$ water bath, the lipid extraction rate at $100{ }^{\circ} \mathrm{C}$ was increased by $3 \%$. Thus, yeast lipids were extracted by the acid-heat method; a $100{ }^{\circ} \mathrm{C}$ hot water bath was selected for the extraction, since this was the best extraction temperature in this study. In addition, according to the literature, ultrasonicassisted extraction is effective in increasing the extraction yield. Figure 5 shows that the lipid extraction yield increased with increasing ultrasonication time; however, ultrasonic extraction was used for $45 \mathrm{~min}$ and the yeast lipid extraction yield only increased by $1 \%$ compared with the extraction done without sonication. Moreover, if the ultrasonic action time was too long, it would also increase the extraction cost. Considering the factors time and cost, the subsequent steps of this research will not use ultrasonic extraction for yeast lipids.

\subsection{Analysis of fatty acid composition of yeast lipid}

The fatty acid composition of yeast lipids was measured by GC/mass analysis, and the results are shown in Table 8. The fatty acid composition of the $R$. mucilaginosa strain comprises mainly oleic acid (C18:1) and palmitic acid (C16:0). In particular, C18:1 could exceed 41\%; this means that the fatty acid composition of $R$. mucilaginosa is similar to those of other oleaginous yeasts, so $R$. mucilaginosa is also a good lipid source for the production of biodiesel. In addition, yeast lipids also contain long-chain fatty acids with C20 and C24 chains. For biodiesel, the composition of fatty acids affects the physical and chemical properties (saponification value and iodine value) and economic value of the lipid, and its composition also affects the quality of the biodiesel (oxidation stability, heat of combustion, and lubricity).

\subsection{DSC thermal analysis of yeast lipid}

Using DSC and the initial temperatures to analyze the thermal characteristics and phase changes of yeast lipids under different thermal conditions, the peak maximum temperatures of endothermic and exothermic reactions and enthalpies of endothermic and exothermic reactions were estimated. Figure 6 shows that yeast lipids have good thermal properties. We found that during heating from 30 to 300 ${ }^{\circ} \mathrm{C}$, the yeast lipid exhibited almost no obvious exothermic or endothermic reaction. In addition, DSC thermal analysis was used to assess the exothermic reaction characteristics of yeast lipids at general operating temperatures. This was done to observe the influences of summer or high operating temperatures on lipids and determine whether condensation would occur at low temperatures. DSC nonthermal analysis conditions were conducted with increase rates of 4,6 , and $8{ }^{\circ} \mathrm{C} / \mathrm{min}$, and the 
temperature rose from 30 to $70{ }^{\circ} \mathrm{C}$ at the beginning of the experiment, stayed at $70{ }^{\circ} \mathrm{C}$ for three minutes to reach a stable state, and then decreased to $-60{ }^{\circ} \mathrm{C}$, as displayed and listed in Table 9. Moreover, from Figure 7 and Table 9, we obtained data regarding cooling from 70 to $-60{ }^{\circ} \mathrm{C}$. There were two obvious exothermic peaks observed during cooling condensation; the first peak, for the condensation crystallization, was at approximately $9{ }^{\circ} \mathrm{C}$ and the enthalpy of crystallization was $24.51 \mathrm{~J} / \mathrm{g}$, and the second peak, for the precipitation solidification, was at ca. $-17{ }^{\circ} \mathrm{C}$ and the enthalpy of solidification was $38.23 \mathrm{~J} / \mathrm{g}$ (at cooling rate of $4{ }^{\circ} \mathrm{C} / \mathrm{min}$ ). From the abovementioned results, we learned that the saturated fatty acids contained in yeast lipids still display the low-temperature characteristics of lipids. Therefore, after the yeast lipid is transesterified, it still needs to be blended with petrochemical fuel to allow the lipid cycles of engines to operate normally at low temperature.

\subsection{Measurement of yeast lipid calorific value and isothermal $40^{\circ} \mathrm{C}$ kinematic viscosity}

A good fuel has a suitable heat of combustion. Here, we put the yeast lipid into an oxygen bomb calorimeter to measure the heat of combustion, averaged the values from triplicate determinations, and then obtained the calorific value of yeast lipid as $38.16 \mathrm{MJ} / \mathrm{kg}$. The carbon chain lengths in gasoline range from $\mathrm{C} 4-\mathrm{C} 12$ the carbon chain lengths in diesel range from $\mathrm{C} 10-\mathrm{C} 22$, and the carbon chain lengths in yeast lipid ranges from $\mathrm{C} 14-\mathrm{C} 24$. The difference in chain length causes the yeast lipid to have a higher calorific value of combustion. Kinematic viscosity is one of the important properties of diesel. If the carbon chain length of the lipid and the molecular weight increase, the kinematic viscosity will increase accordingly. Based on the results of the kinematic viscosity measurements run in triplicate, the kinematic viscosity of the yeast lipid (not yet transesterified) was $49.04 \mathrm{~mm}^{2} / \mathrm{s}$.

The higher kinematic viscosity value, which indicates lower fluidity, may cause the fuel to stick in the fuel pipe or stick to the wall of the fuel cylinder, which will have an adverse effect on the engine. The solution is to blend the biodiesel with petrochemical fuel, but the kinematic viscosity of the diesel should not be too low. Because parts of the high-pressure fuel injection system are lubricated by diesel, poor lubrication will cause the parts to wear excessively. Biodiesel with a high kinematic viscosity must be blended with petrochemical diesel in a certain proportion to reduce the kinematic viscosity value to within the range specified in biodiesel regulations (1.9 to $\left.6.0 \mathrm{~mm}^{2} / \mathrm{s}\right)$. According to the method of Tsai et al. (2015) (previous research) [34], transesterifying yeast lipids to be made into biodiesel reduces the kinematic viscosity value of yeast lipid biodiesel to $6.37 \mathrm{~mm}^{2} / \mathrm{s}$.

\section{Conclusion}

Overall, this study investigated the relationships between different nutrient elements and the growth of $R$. mucilaginosa. R. mucilaginosa exhibited higher lipid accumulation under nitrogenrestricted conditions, but the increase in carbon source concentration promoted the accumulation of 
lipids. However, a further increase in the concentration of the carbon source inhibited the growth of yeast. Therefore, the sampling of the shake flask fermentation was done in the 6th day, and culturing was done with glucose as the carbon source, an initial carbon source concentration of $60 \mathrm{~g} / \mathrm{L}$, an initial nitrogen source concentration of $0.5 \mathrm{~g} / \mathrm{L}$, and a $\mathrm{KH}_{2} \mathrm{PO}_{4}$ concentration of $7.0 \mathrm{~g} / \mathrm{L}$. The accumulation of yeast lipids reached a maximum with these conditions. In addition, the selection of extraction method and solvent affected the extraction of $R$. mucilaginosa lipids. We determined that the acidthermal extraction method had the best effect: ethyl acetate had a higher lipid extraction efficiency than n-hexane and was also more efficient than a methylene chloride:methanol mixture, and it is less toxic and safer to operate. From the analysis of fatty acid composition of yeast lipids, the fatty acids mainly included C16:0, C18:1 (41\%), and C18:2, which showed that $R$. mucilaginosa lipids are a good raw material for the production of biodiesel. Furthermore, the thermal stability and low-temperature physical characteristics of $R$. mucilaginosa lipids were also used as a reference to determine safe conditions for production, storage, and transportation of biodiesel. It is also known that yeast lipids have good thermal stability, high calorific value and suitable kinematic viscosity (biodiesel). Therefore, R. mucilaginosa lipids have excellent prospects for the production of biodiesel. We believe that with additional research, cultivation technology and methods will become more mature. As a result of larger scale cultivation, increases in the production of lipids by $R$. mucilaginosa will be gradually realized, ensuring that the biofuels produced from oil-producing microbial raw materials are cost-effective, environmentally friendly, and sustainable. 


\section{Table captions}

Table 1. The growth of $R$. mucilaginosa dried cell extract.

Table 2. Effects of different initial reducing sugar concentrations on the growth and lipid accumulation of $R$. mucilaginosa.

Table 3. Effects of different nitrogen source concentrations on the biomass and lipid contents of $R$. mucilaginosa.

Table 4. Influences of different $\mathrm{KH}_{2} \mathrm{PO}_{4}$ concentrations on the biomass and lipid contents of $R$. mucilaginosa.

Table 5. Comparison of $R$. mucilaginosa lipid content obtained with different extraction methods.

Table 6. Comparison of $R$. mucilaginosa lipid content obtained with the acid-heat method and different extraction solvents.

Table 7. Differences in the $R$. mucilaginosa lipid contents of yeast cells obtained with various concentrations of hydrochloric acid.

Table 8. Fatty acid composition of lipid extracted from $R$. mucilaginosa

Table 9. DSC analysis results for $R$. mucilaginosa lipids with heating rates at $2,4,6$ and $8{ }^{\circ} \mathrm{C} / \mathrm{min}$, with operating temperature ranging from 30 to $70{ }^{\circ} \mathrm{C}$ and then cooling to $-60{ }^{\circ} \mathrm{C}$ 
Table 1. The growth of $R$. mucilaginosa dried cell extract.

\begin{tabular}{cccc}
\hline Day & $\begin{array}{c}\text { Biomass } \\
(\mathrm{g} / 100 \mathrm{~mL})\end{array}$ & $\begin{array}{c}\text { Lipid yield } \\
(\mathrm{g} / 100 \mathrm{~mL})\end{array}$ & $\begin{array}{c}\text { Lipid content } \\
(\%)\end{array}$ \\
\hline 2 & $0.37 \pm 0.00$ & $0.04 \pm 0.00$ & $10.72 \pm 0.74$ \\
4 & $0.80 \pm 0.11$ & $0.09 \pm 0.01$ & $10.92 \pm 0.44$ \\
6 & $0.99 \pm 0.07$ & $0.12 \pm 0.00$ & $12.51 \pm 0.55$ \\
8 & $1.14 \pm 0.01$ & $0.13 \pm 0.01$ & $11.28 \pm 0.38$ \\
\hline
\end{tabular}

Table 2. Effects of different initial reducing sugar concentrations on the growth and lipid accumulation of $R$. mucilaginosa

\begin{tabular}{cccc}
\hline $\begin{array}{c}\text { Carbon concentration } \\
(\mathrm{g} / \mathrm{L})\end{array}$ & $\begin{array}{c}\text { Biomass } \\
(\mathrm{g} / 100 \mathrm{~mL})\end{array}$ & $\begin{array}{c}\text { Lipid yield } \\
(\mathrm{g} / 100 \mathrm{~mL})\end{array}$ & $\begin{array}{c}\text { Lipid content } \\
(\%)\end{array}$ \\
\hline 40 & $0.60 \pm 0.02$ & $0.07 \pm 0.00$ & $12.30 \pm 0.45$ \\
60 & $0.62 \pm 0.01$ & $0.09 \pm 0.00$ & $14.86 \pm 0.17$ \\
80 & $0.62 \pm 0.01$ & $0.08 \pm 0.01$ & $13.43 \pm 0.66$ \\
100 & $0.62 \pm 0.01$ & $0.09 \pm 0.01$ & $14.17 \pm 0.80$ \\
\hline
\end{tabular}

Table 3. Effects of different nitrogen source concentrations on biomass and lipid content of $R$. mucilaginosa

\begin{tabular}{cccc}
\hline $\begin{array}{c}\text { Nitrogen } \\
\text { concentration }(\mathrm{g} / \mathrm{L})\end{array}$ & $\begin{array}{c}\text { Biomass } \\
(\mathrm{g} / 100 \mathrm{~mL})\end{array}$ & $\begin{array}{c}\text { Lipid yield } \\
(\mathrm{g} / 100 \mathrm{~mL})\end{array}$ & $\begin{array}{c}\text { Lipid content } \\
(\%)\end{array}$ \\
\hline 0.5 & $0.60 \pm 0.00$ & $0.10 \pm 0.00$ & $16.11 \pm 0.64$ \\
1.0 & $0.69 \pm 0.05$ & $0.07 \pm 0.01$ & $10.32 \pm 0.43$ \\
1.5 & $0.76 \pm 0.06$ & $0.08 \pm 0.00$ & $10.25 \pm 0.22$ \\
2.0 & $0.71 \pm 0.03$ & $0.07 \pm 0.00$ & $9.92 \pm 0.09$ \\
\hline
\end{tabular}


Table 4. Influences of different $\mathrm{KH}_{2} \mathrm{PO}_{4}$ concentrations on the biomass and lipid content of $R$. mucilaginosa

\begin{tabular}{cccc}
\hline $\begin{array}{c}\mathrm{KH}_{2} \mathrm{PO}_{4} \\
\text { concentration }(\mathrm{g} / \mathrm{L})\end{array}$ & $\begin{array}{c}\text { Biomass } \\
(\mathrm{g} / 100 \mathrm{~mL})\end{array}$ & $\begin{array}{c}\text { Lipid yield } \\
(\mathrm{g} / 100 \mathrm{~mL})\end{array}$ & $\begin{array}{c}\text { Lipid content } \\
(\%)\end{array}$ \\
\hline 1.0 & $0.43 \pm 0.00$ & $0.08 \pm 0.01$ & $19.08 \pm 1.24$ \\
3.0 & $0.45 \pm 0.01$ & $0.10 \pm 0.01$ & $21.30 \pm 0.89$ \\
7.0 & $0.59 \pm 0.01$ & $0.15 \pm 0.03$ & $25.51 \pm 2.07$ \\
\hline
\end{tabular}

Table 5. Comparison of $R$. mucilaginosa lipid content obtained with different extraction methods

\begin{tabular}{lcc}
\hline Extraction method & $\begin{array}{c}\text { Lipid yield } \\
(\mathrm{g} / 100 \mathrm{~mL})\end{array}$ & $\begin{array}{c}\text { Lipid content } \\
(\%)\end{array}$ \\
\hline Soxhlet & $0.04 \pm 0.01$ & $7.90 \pm 0.15$ \\
Organic solvent & $0.06 \pm 0.02$ & $11.38 \pm 0.49$ \\
Acid-heat method & $0.07 \pm 0.01$ & $14.85 \pm 0.26$ \\
\hline
\end{tabular}

Table 6. Comparison of $R$. mucilaginosa lipid content obtained with the acid-heat method and different extraction solvents.

\begin{tabular}{lcc}
\hline Organic solvent & $\begin{array}{c}\text { Lipid yield } \\
(\mathrm{g} / 100 \mathrm{~mL})\end{array}$ & $\begin{array}{c}\text { Lipid content } \\
(\%)\end{array}$ \\
\hline Dichloromethane: methanol $(1: 1)$ & $0.09 \pm 0.01$ & $18.56 \pm 1.13$ \\
Ethyl acetate & $0.09 \pm 0.00$ & $18.80 \pm 0.03$ \\
N-hexane & $0.08 \pm 0.01$ & $15.80 \pm 0.25$ \\
\hline
\end{tabular}


Table 7. Differences in the R. mucilaginosa lipid contents of yeast cells obtained with various concentrations of hydrochloric acid

\begin{tabular}{ccc}
\hline $\begin{array}{c}\text { Hydrochloric acid concentration } \\
(\mathrm{M})\end{array}$ & $\begin{array}{c}\text { Lipid yield } \\
(\mathrm{g} / 100 \mathrm{~mL})\end{array}$ & $\begin{array}{c}\text { Lipid content } \\
(\%)\end{array}$ \\
\hline 1 & $0.07 \pm 0.01$ & $11.43 \pm 0.60$ \\
2 & $0.09 \pm 0.01$ & $15.08 \pm 1.14$ \\
3 & $0.11 \pm 0.01$ & $18.29 \pm 0.46$ \\
4 & $0.12 \pm 0.00$ & $20.29 \pm 0.32$ \\
\hline
\end{tabular}

Table 8. Fatty acid composition of lipids extracted from R. mucilaginosa

\begin{tabular}{lcc}
\hline Fatty acid & Form & $\%$ \\
\hline Myristic acid & C14:0 & 1.08 \\
Palmitic acid & C16:0 & 15.85 \\
Palmitoleic acid & C16:1 & 1.92 \\
Stearic acid & C18:0 & 0.86 \\
Oleic acid & $\mathrm{C} 18: 1$ & 41.44 \\
Linoleic acid & $\mathrm{C} 18: 2$ & 10.35 \\
Linolenic acid & $\mathrm{C} 18: 3$ & 0.97 \\
Eicosenoic acid & $\mathrm{C} 20: 1$ & 0.25 \\
Lignoceric acid & $\mathrm{C} 24: 0$ & 0.65 \\
\hline Total saturation & & 18.45 \\
Total monounsaturated & & 43.61 \\
Total polyunsaturated & & 11.32 \\
\hline
\end{tabular}

Table 9. DSC analysis results for $R$. mucilaginosa lipids with heating rates of $2,4,6$ and $8{ }^{\circ} \mathrm{C} / \mathrm{min}$, with operating temperature ranging from 30 to $70{ }^{\circ} \mathrm{C}$, and then cooling to $-60{ }^{\circ} \mathrm{C}$

\begin{tabular}{cccccccc}
\hline $\begin{array}{c}\text { Mass } \\
(\mathrm{mg})\end{array}$ & $\begin{array}{c}\text { Cooling rate } \\
\left({ }^{\circ} \mathrm{C} / \mathrm{min}\right)\end{array}$ & $\begin{array}{c}1 \text { exo } T_{\text {onset }} \\
\left({ }^{\circ} \mathrm{C}\right)\end{array}$ & $\begin{array}{c}\text { exo } T_{\text {peak }} \\
\left({ }^{\circ} \mathrm{C}\right)\end{array}$ & $\begin{array}{c}\text { 1Enthalpy } \\
(\mathrm{J} / \mathrm{g})\end{array}$ & $\begin{array}{c}2 e x o T_{\text {onset }} \\
\left({ }^{\circ} \mathrm{C}\right)\end{array}$ & $\begin{array}{c}2 e x o T_{\text {peak }} \\
\left({ }^{\circ} \mathrm{C}\right)\end{array}$ & $\begin{array}{c}2 \text { Enthalpy } \\
(\mathrm{J} / \mathrm{g})\end{array}$ \\
\hline 1.50 & 4 & 8.94 & 8.30 & 24.51 & -17.15 & -18.06 & 38.23 \\
1.45 & 6 & 9.08 & 8.34 & 21.16 & -16.43 & -17.19 & 37.94 \\
1.48 & 8 & 9.20 & 8.61 & 26.25 & -17.19 & -18.19 & 42.54 \\
\hline
\end{tabular}

Remarks: Standard deviation: temperature accuracy: $+/-0.1$; temperature precision: $+/-0.05$ calorimetric reproducibility: $+/-1$ mass\%; sensitivity: $1.0 \mathrm{uW}$. 


\section{Figure captions}

Figure 1. $R$. mucilaginosa strain morphology (a) cultured in solid medium, (b) yeast cell at 400X magnification, (c) yeast grown in liquid medium on days $0,3,6,9,12$, and 15

Figure 2. $R$. mucilaginosa dry cells extracted relative to the growth curves of $R$. mucilaginosa

Figure 3. Effects of different carbon sources on the biomass and lipid content of $R$. mucilaginosa (carbon source concentration $60 \mathrm{~g} / \mathrm{L}$ )

Figure 4. Influences of hot water bath temperature on the lipid extraction efficiency of $R$. mucilaginosa (hydrochloric acid concentration $4 \mathrm{M}$ )

Figure 5. Effect of ultrasonic extraction time on the lipid content of $R$. mucilaginosa (hot water bath $\left.100^{\circ} \mathrm{C}\right)$

Figure 6. $R$. mucilaginosa lipids analyzed by DSC at heating rates of 4,6 , and $8^{\circ} \mathrm{C} / \mathrm{min}$, with the temperature ranging from 30 to $300{ }^{\circ} \mathrm{C}$.

Figure 7. R. mucilaginosa lipids measured with DSC with heating rates of $2,4,6$, and $8{ }^{\circ} \mathrm{C} / \mathrm{min}$, with the operating temperature ranging from 30 to $70{ }^{\circ} \mathrm{C}$ and then cooling to $-60{ }^{\circ} \mathrm{C}$. 

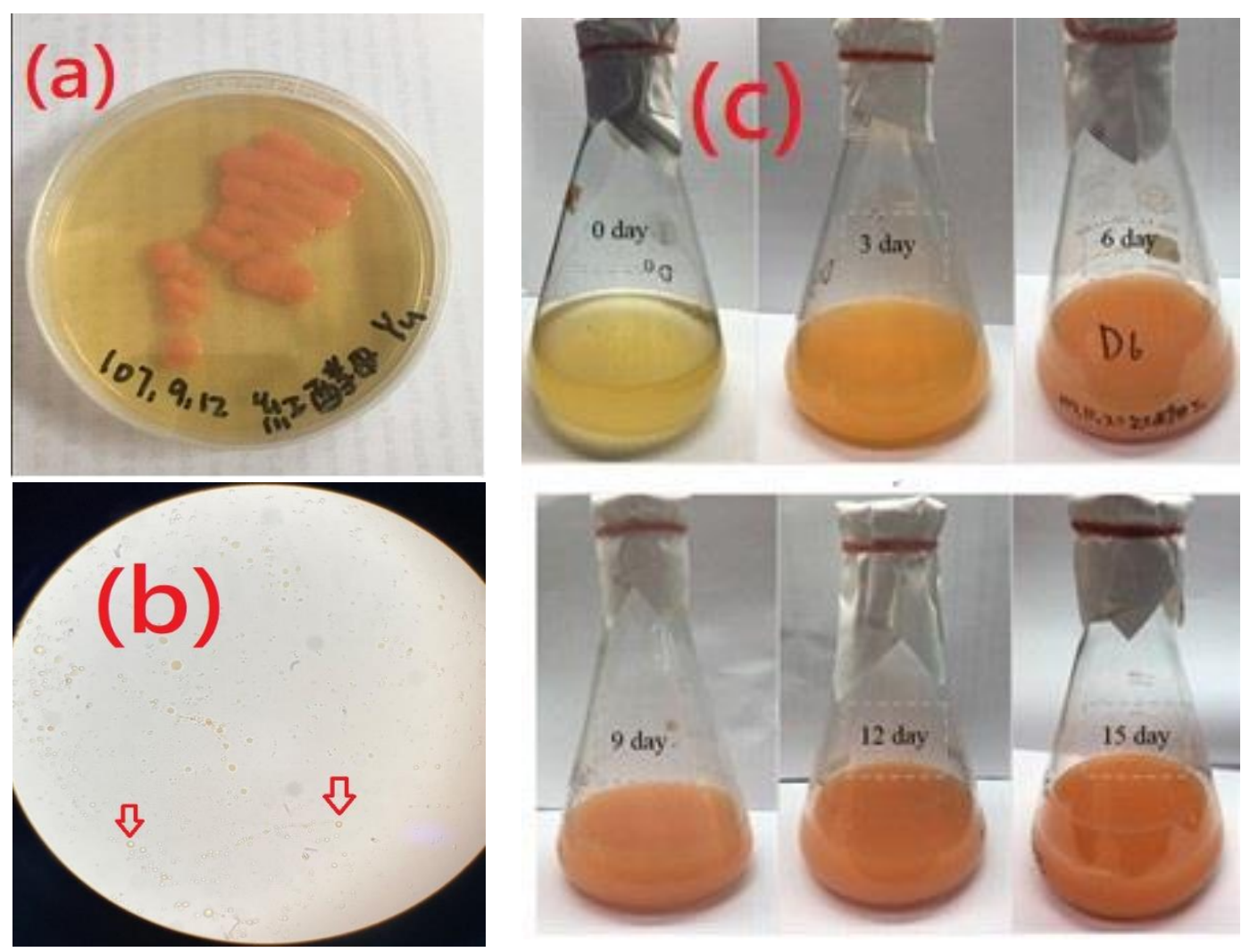

Figure 1. R. mucilaginosa strain morphology (a) cultured in solid medium, (b) yeast cell at 400X magnification, (c) yeast grown in liquid medium on days $0,3,6,9,12$, and 15

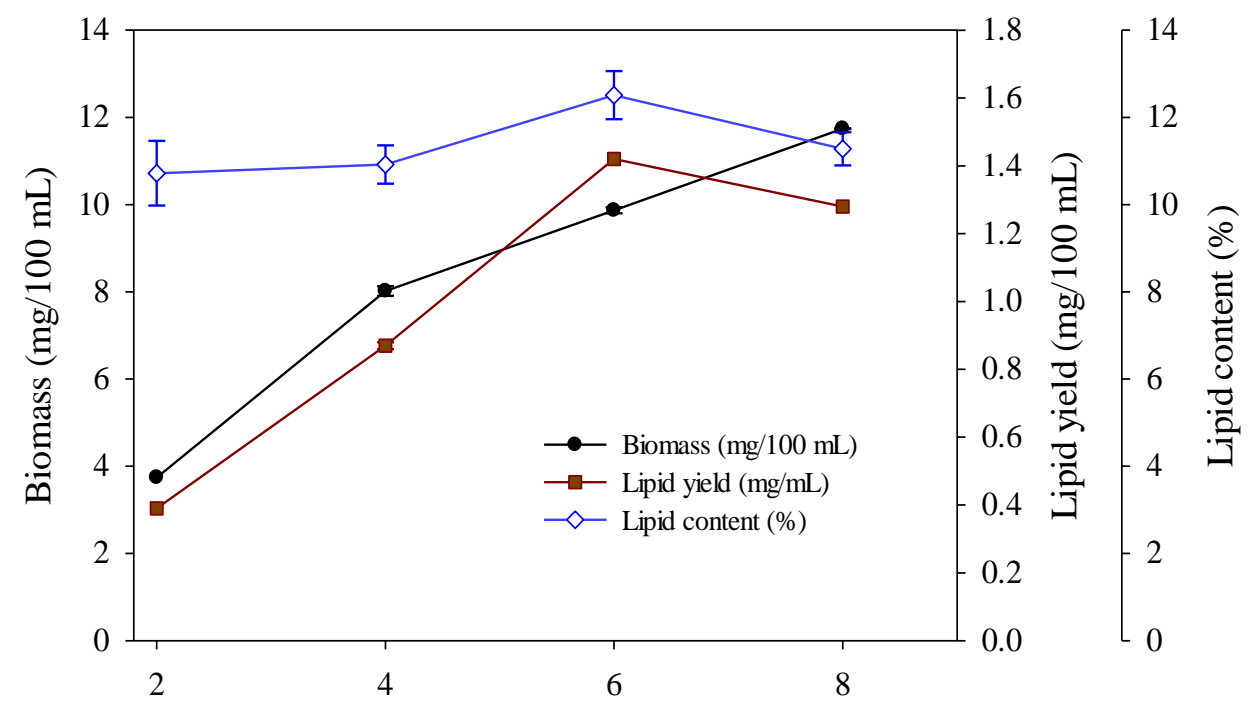

Figure 2. $R$. mucilaginosa dry cells extracted relative to the growth curves of $R$. mucilaginosa. 


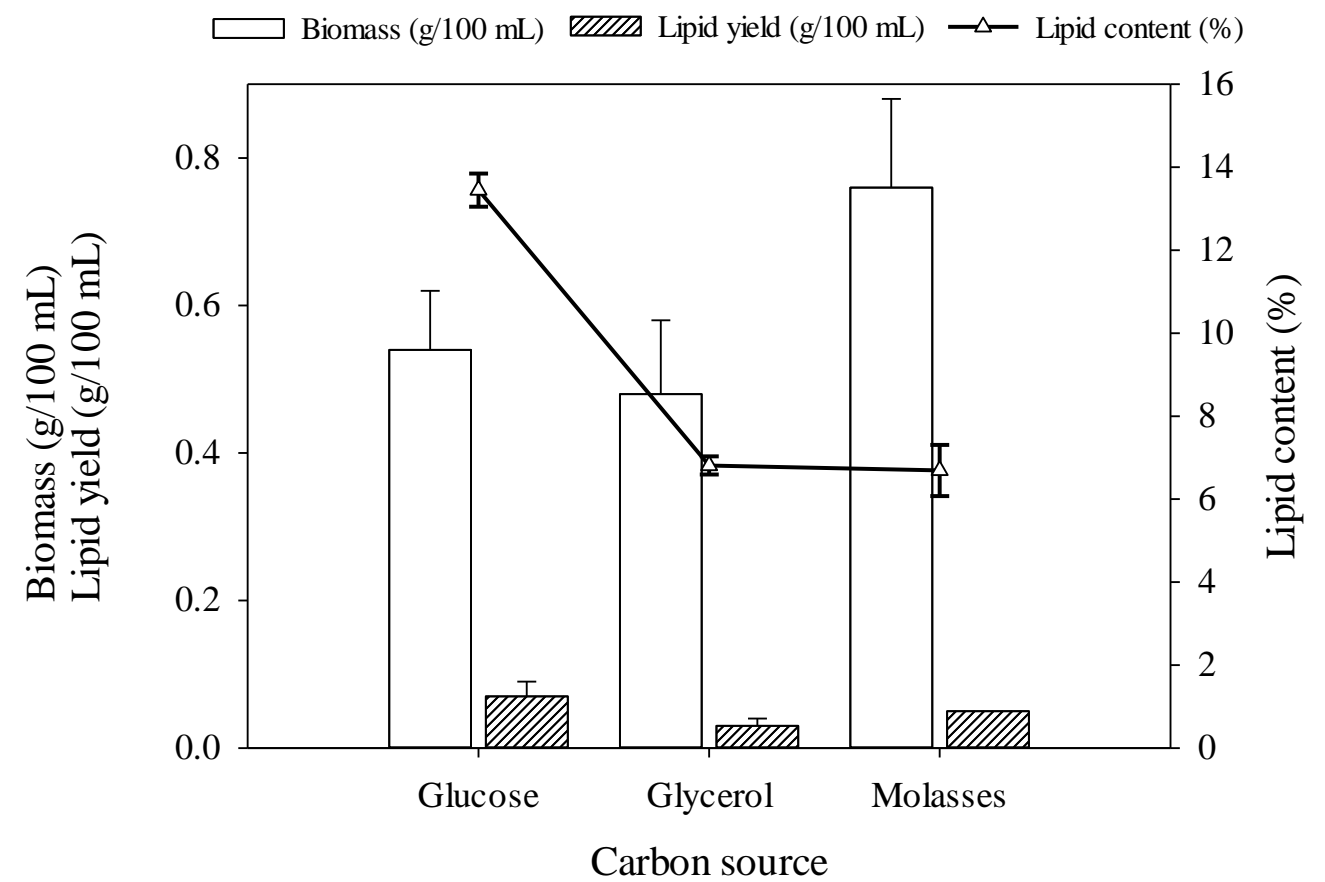

Figure 3. Effects of different carbon sources on the biomass and lipid content of $R$. mucilaginosa (carbon source concentration $60 \mathrm{~g} / \mathrm{L}$ ).

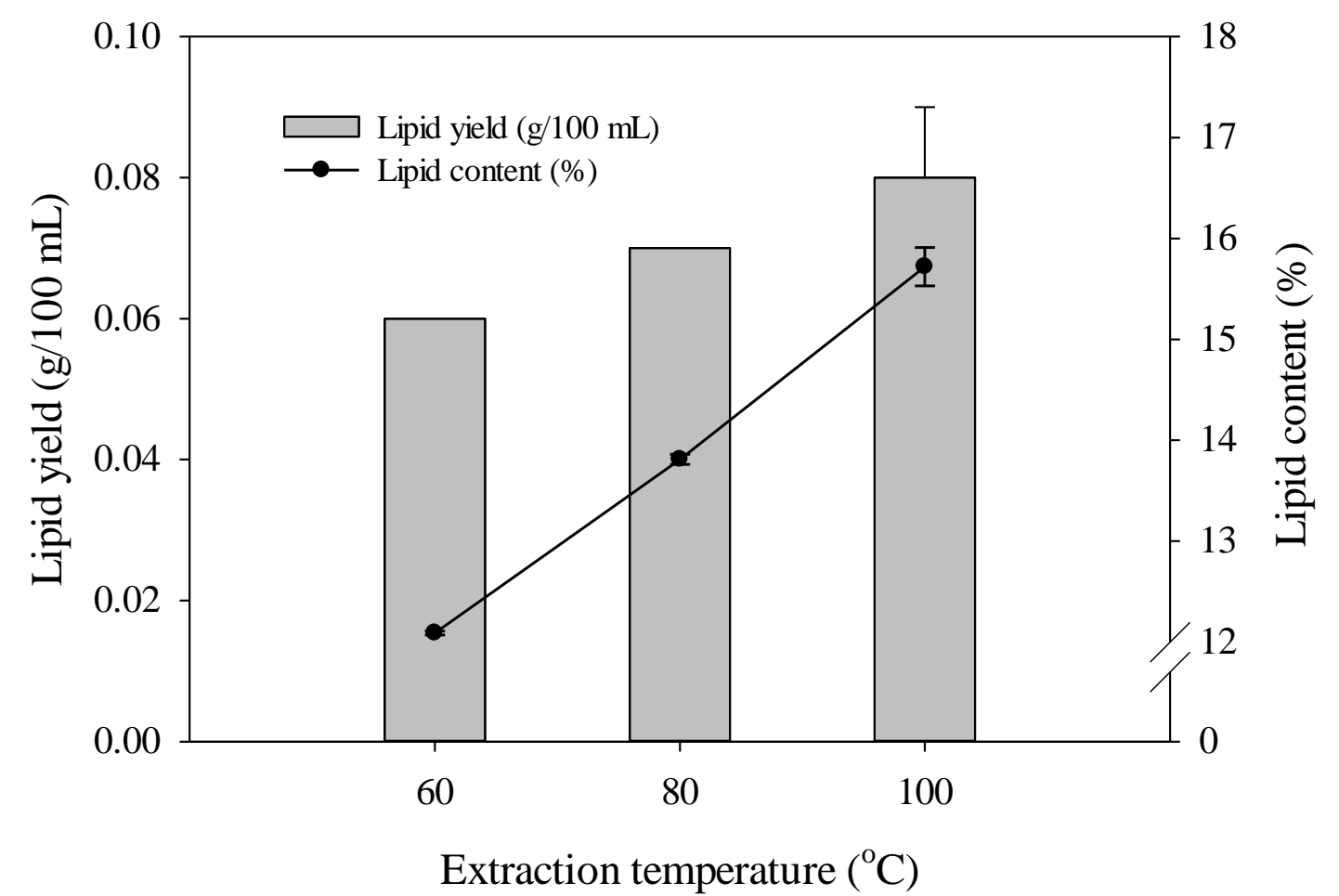

Figure 4. Influence of hot water bath temperature on the lipid extraction efficiency of $R$. mucilaginosa (hydrochloric acid concentration $4 \mathrm{M}$ ) 


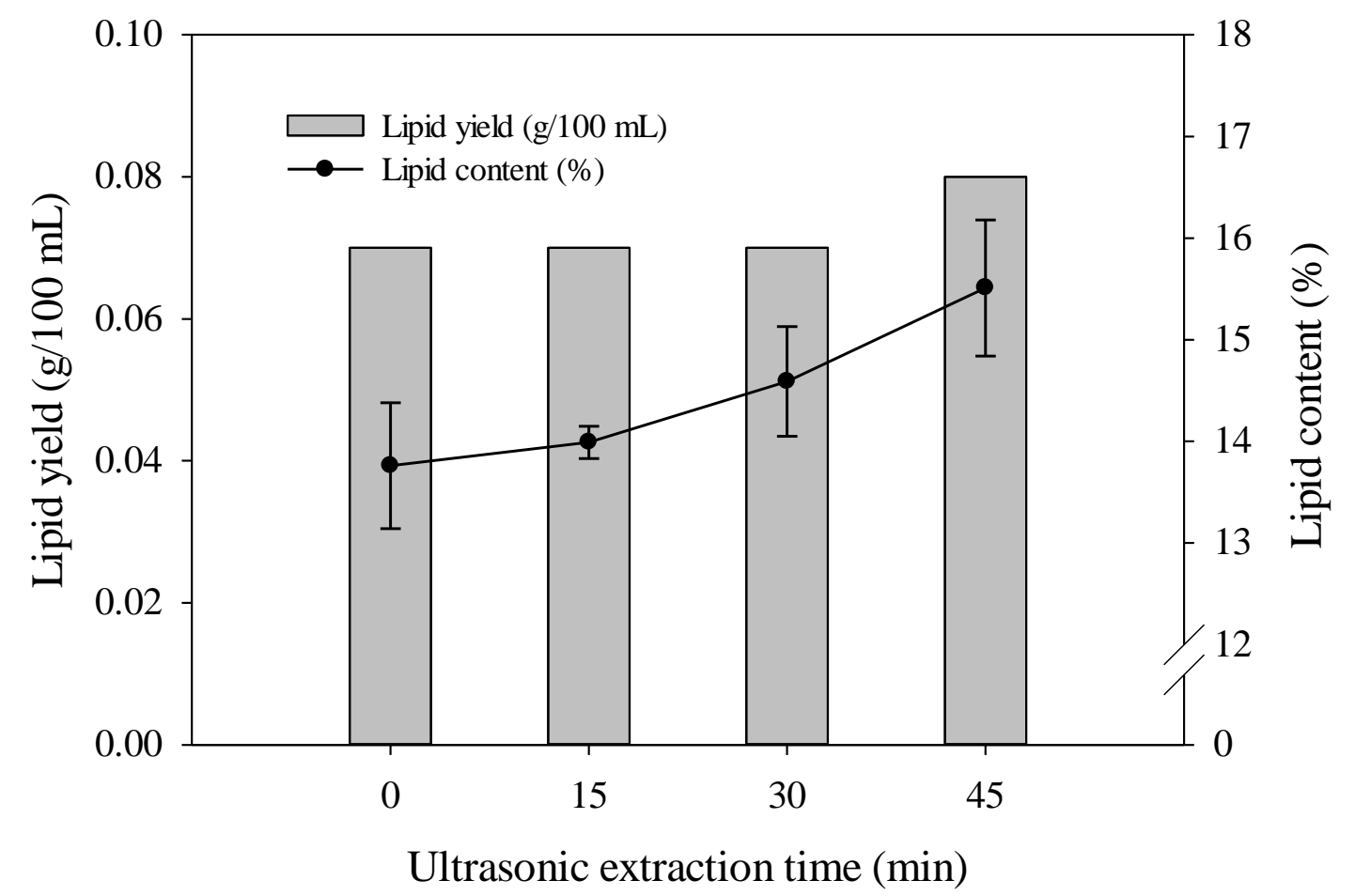

Figure 5. Effect of ultrasonic extraction time on the lipid content of $R$. mucilaginosa (hot water bath $\left.100{ }^{\circ} \mathrm{C}\right)$

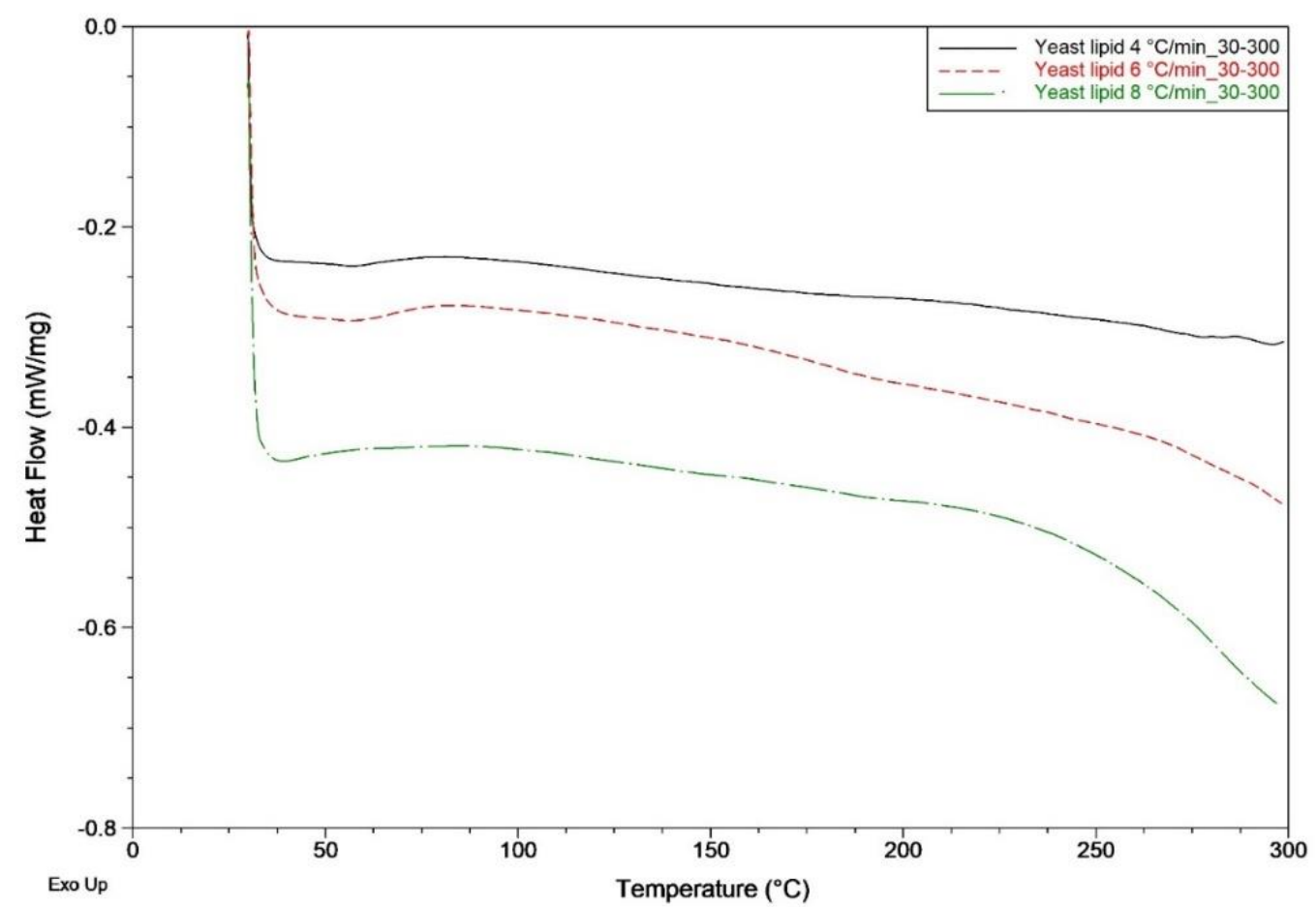

Figure 6. $R$. mucilaginosa lipids analyzed by DSC with heating rates of 4,6 , and $8{ }^{\circ} \mathrm{C} / \mathrm{min}$, with the temperature ranging from 30 to $300{ }^{\circ} \mathrm{C}$. 


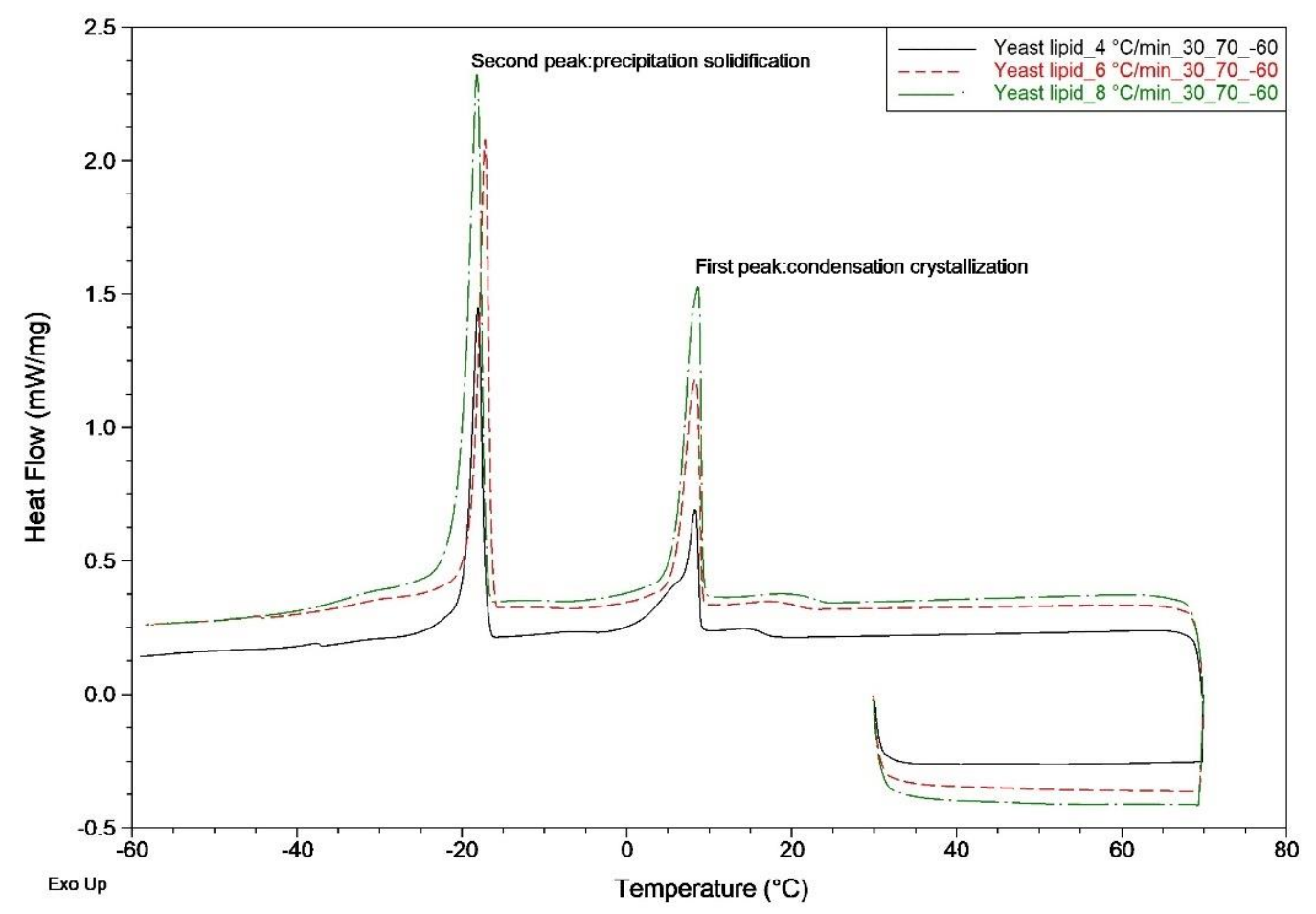

Figure 7. R. mucilaginosa lipids measured with DSC heating rates of $2,4,6$, and $8{ }^{\circ} \mathrm{C} / \mathrm{min}$, with the operating temperature ranging from 30 to $70^{\circ} \mathrm{C}$, and then cooling to $-60{ }^{\circ} \mathrm{C}$. 


\section{References}

1. Bandhu, S.; Bansal, N.; Dasgupta, D.; Junghare, V.; Sidana, A.; Kalyan, G.; Hazra, S.; Ghosh, D. Overproduction of single cell oil from xylose rich sugarcane bagasse hydrolysate by an engineered oleaginous yeast Rhodotorula mucilaginosa IIPL32. Fuel. 2019, 254, 115653.

2. Li, M.; Liu, G.L.; Chi, Z.; Chi, Z.M. Single cell oil production from hydrolysate of cassava starch by marine-derived yeast Rhodotorula mucilaginosa TJY15a. Biomass and Bioenergy. 2010, 34(1), 101-107.

3. Kitcha, S.; Cheirsilp, B. Screening of oleaginous yeasts and optimization for lipid production using crude glycerol as a carbon source. Energy Procedia. 2011, 9, 274-282.

4. Bandhu, S.; Dasgupta, D.; Akhter, J.; Kanaujia, P.; Suman, S.K.; Agrawal, D.; Kaul, S.; Adhikari, D.K.; Ghosh, D. Statistical design and optimization of single cell oil production from sugarcane bagasse hydrolysate by an oleaginous yeast Rhodotorula sp. IIP-33 using response surface methodology. SpringerPlus. 2014, 3(1), 691.

5. Santamauro, F.; Whiffin, F.M.; Scott, R.J.; Chuck, C.J. Low-cost lipid production by an oleaginous yeast cultured in non-sterile conditions using model waste resources.

Biotechnology for Biofuels. 2014, 7(1), 34.

6. Annamalai, N.; Sivakumar, N.; Oleskowicz-Popiel, P. Enhanced production of microbial lipids from waste office paper by the oleaginous yeast Cryptococcus curvatus. Fuel. 2018, 217, 420-426.

7. Saenge, C.; Cheirsilp, B.; Suksaroge, T.T.; Bourtoom, T. Potential use of oleaginous red yeast Rhodotorula glutinis for the bioconversion of crude glycerol from biodiesel plant to lipids and carotenoids. Process Biochemistry. 2011, 46(1), 210-218.

8. Saran, S.; Mathur, A.; Dalal, J.; Saxena, R.K. Process optimization for cultivation and oil accumulation in an oleaginous yeast Rhodosporidium toruloides A29. Fuel. 2017, 188, 324-331.

9. Subramaniam, R.; Dufreche, S.; Zappi, M.; Bajpai, R. Microbial lipids from renewable resources: production and characterization. Journal of Industrial Microbiology and Biotechnology. 2010, 37(12), 1271-1287.

10. Tkachenko, A.F.; Tigunova, O.A.; Shulga, S.M. Microbial lipids as a source of biofuel. Cytology and genetics. 2013, 47(6), 343-348.

11. Leiva-Candia, D.E.; Pinzi, S.; Redel-Macías, M.D.; Koutinas, A.; Webb, C.; Dorado, M.P. The potential for agro-industrial waste utilization using oleaginous yeast for the production of biodiesel. Fuel, 2014, 123, 33-42.

12. Prabhu, A.A.; Gadela, R.; Bharali, B.; Deshavath, N.N.; Dasu, V.V. Development of high biomass and lipid yielding medium for newly isolated Rhodotorula mucilaginosa. Fuel. 2019, 239, 874-885.

13. Pacia, M.Z.; Pukalski, J.; Turnau, K.; Baranska, M.; Kaczor, A. Lipids, hemoproteins and carotenoids in alive Rhodotorula mucilaginosa cells under pesticide decomposition-Raman imaging study. Chemosphere. 2016, 164, 1-6.

14. Anschau, A. Lipids from oleaginous yeasts: production and encapsulation. Nutrient Delivery. 2017, 749-794.

15. Ageitos, J.M.; Vallejo, J.A.; Veiga-Crespo, P.; Villa, T.G. Oily yeasts as oleaginous cell factories. Applied Microbiology and Biotechnology. 2011, 90(4), 1219-1227.

16. Kong, W.; Song, H.; Cao, Y.; Yang, H.; Hua, S.; Xia, C. The characteristics of biomass production, lipid accumulation and chlorophyll biosynthesis of Chlorella vulgaris under mixotrophic cultivation. African Journal of Biotechnology. 2011, 10(55),11620-11630

17. Leong, W.H.; Lim, J.W.; Lam, M.K.; Uemura, Y.; Ho, Y.C. Third generation biofuels: A nutritional perspective in enhancing microbial lipid production. Renewable and Sustainable Energy reviews. 2018, 91, 950-961.

18. Liang, M.H.; Jiang, J.G. Advancing oleaginous microorganisms to produce lipid via metabolic engineering technology. Progress in Lipid Research. 2013, 52(4), 395-408. 
19. Xing, D.; Wang, H.; Pan, A.; Wang, J.; Xue, D. Assimilation of corn fiber hydrolysates and lipid accumulation by Mortierella isabellina. Biomass and bioenergy. 2012, 39, 494-501.

20. Quigg, A. Micronutrients. The Physiology of Microalgae. 2016, 211-231.

21. Henderson, R.K.; Jiménez-González, C.; Constable, D.J.; Alston, S.R.; Inglis, G.G.; Fisher, G.; Sherwood, J.; Binks, S.P.; Curzons, A.D. (2011). Expanding GSK's solvent selection guide-embedding sustainability into solvent selection starting at medicinal chemistry. Green Chemistry. 2011, 13(4), 854-862.

22. Alder, C. M.; Hayler, J.D.; Henderson, R.K.; Redman, A.M.; Shukla, L., Shuster, L.E.; Sneddon, H.F. Updating and further expanding GSK's solvent sustainability guide. Green Chemistry, 2016, 18(13), 3879-3890.

23. Cseri, L.; Razali, M.; Pogany, P.; Szekely, G. Organic solvents in sustainable synthesis and engineering. Green Chemistry. 2018, 513-553.

24. Park, J.; Kim, B.; Chang, Y.K.; Lee, J.W. Wet in situ transesterification of microalgae using ethyl acetate as a co-solvent and reactant. Bioresource Technology. 2017, 230:8-14.

25. Lu, W.; Alam, M.A.; Pan, Y.; Nock, W.J.; Wang, Z.; Yuan, Z. Optimization of algal lipid extraction by mixture of ethyl acetate and ethanol via response surface methodology for biodiesel production. Korean Journal of Chemical Engineering, 2016, 33(9), 2575-2581.

26. Lu, W.; Wang, Z.; Yuan, Z. Characteristics of lipid extraction from Chlorella sp. cultivated in outdoor raceway ponds with mixture of ethyl acetate and ethanol for biodiesel production. Bioresource Technology. 2015, 191, 433-437.

27. Fine, F.; Vian, M.A.; Tixier, A.S.F.; Carre, P.; Pages, X.; Chemat, F. Les agro-solvants pour l'extraction des huiles vegetales issues de graines oléagineuses. Oilseeds and fats, Crops and Lipids. 2013, 20(5), 1-6.

28. Lohani, U.C.; Fallahi, P.; Muthukumarappan, K. Comparison of ethyl acetate with hexane for oil extraction from various oilseeds. Journal of the American Oil Chemists' Society, 2015, 92(5), 743-754.

29. Jiyane, P.C.; Tumba, K.; Musonge, P. Optimisation of Croton gratissimus oil extraction by n-hexane and ethyl acetate using response surface methodology. Journal of Oleo Science, 2018, 67(4), 369-377.

30. Xu, L.; Brilman, D.W.W.; Withag, J.A.; Brem, G.; Kersten, S. Assessment of a dry and a wet route for the production of biofuels from microalgae: energy balance analysis. Bioresource Technology. 2011, 102(8), 5113-5122.

31. Teo, C.L.; Idris, A. Enhancing the various solvent extraction method via microwave irradiation for extraction of lipids from marine microalgae in biodiesel production. Bioresource Technology. 2014, 171, 477-481.

32. Deshmukh, S.; Kumar, R.; Bala, K. Microalgae biodiesel: A review on oil extraction, fatty acid composition, properties and effect on engine performance and emissions. Fuel Processing Technology. 2019, 191, 232-247.

33. Lee, I.; Han, J.I. The effects of waste-activated sludge pretreatment using hydrodynamic cavitation for methane production. Ultrasonics Sonochemistry. 2013, 20(6), 1450-1455.

34. Tsai, S.Y.; Lin H.Y.; Lu G.Y.; Lin, C.P. Solid byproducts of Aurantiochytrium sp. oil made into the biodiesel. Journal of Thermal Analysis and Calorimetry. 2015, 120, 563-572

35. Tsai, S.Y. Tsay, G.J.; Li, C.Y.; Hung, Y.T.; Lin, C.P. Assessment of melting kinetics of sugar-reduced silver ear mushroom ice cream under various additive models. Applied Sciences. 2020, 10, 2664.

Author Contributions: Conceptualization, S.-Y.T.; methodology, C.-P.L. and H.-T. Y.; writingoriginal draft, C.-P.L. and H.-T.Y.; writing — review and editing, S.-Y.T. and C.-P.L.

Acknowledgments: The authors are grateful to the Ministry of Science and Technology (MOST) for providing funding under contract nos. MOST107-2221-E-468 -007 -MY2 and 109-2221-E$468-002-\mathrm{MY} 2$. 
Conflict of Interest: The authors declare no conflicts of interest. 